\title{
Televisão e autogestão: dois caminhos trilhados pelo catolicismo no Brasil
}

\section{Television and self-management: two paths followed by Catholicism in Brazil}

\section{Televisión y autogestión: dos caminos seguidos por el catolicismo en Brasil}

\author{
(iD) André Ricardo de Souza \\ Universidade Federal de São Carlos, São Carlos, São Paulo, Brasil \\ anrisouza@uol.com.br \\ (iD) Breno Minelli Batista \\ Universidade Federal de São Carlos, São Carlos, São Paulo, Brasil \\ breno_minelli@hotmail.com \\ iD) Giulliano Placeres \\ Universidade Federal de São Carlos, São Carlos, São Paulo, Brasil \\ giulliano14@hotmail.com
}

\begin{abstract}
Resumo: Com continuada redução de adeptos, o catolicismo permanece como maioria numérica no campo religioso brasileiro. Tal maioria exerce relevante participação em atividades, desde as exclusivamente religiosas até as seculares, nas áreas de política e economia. Produzido a partir de sistemática revisão bibliográfica, bem como pesquisa documental e análise de dados colhidos em trabalho de campo, o presente artigo objetiva a reflexão acerca de duas frentes distintas de ação política católica contemporânea. É feita uma reflexão acerca das práticas do catolicismo da libertação, seu engajamento político de esquerda e sua participação incisiva no movimento de economia solidária, através da Cáritas Brasileira. Posteriormente, como um contraponto, são analisados os laços políticos existentes entre agentes religiosos e parlamentares para a formação e
\end{abstract}


sustentação das emissoras televisivas carismáticas Canção Nova e TV Século XXI.

Palavras-chave: Catolicismo brasileiro. Teologia da Libertação. Renovação Carismática Católica. Economia solidária. Mídias televisivas católicas.

Abstract: With continued reduction of adherents, Catholicism remains as a numerical majority in the Brazilian religious field. This majority has relevant participation in activities ranging from exclusively religious to secular in the areas of politics and economy. Produced from systematic literature review, as well as documentary research and analysis data collected in field work, this article aims to reflect on two distinct fronts of contemporary Catholic political action. A reflection is made about the practices of liberation catholicism, its leftist political engagement and its incisive participation in the solidarity economy movement, through the Brazilian Caritas. Subsequently, as a counterpoint, the political ties between religious and parliamentary agents for the formation and support of the charismatic television stations Canção Nova and TV Século XXI are analyzed.

Keywords: Brazilian Catholicism. Liberation Theology. Catholic Charismatic Renewal. Solidarity Economy. Catholic Television Media.

Resumen: Con la continua reducción de adherentes, el catolicismo permanece como una mayoría numérica en el campo religioso brasileño. Esta mayoría tiene participación relevante en actividades que van desde exclusivamente religiosas hasta laicas en las áreas de política y economía. Producido a partir de la revisión sistemática de la literatura, así como de la investigación documental y los datos de análisis recopilados en el trabajo de campo, este artículo tiene como objetivo reflexionar sobre dos frentes distintos de la acción política católica contemporánea. Se reflexiona sobre las prácticas de catolicismo de liberación, su compromiso político de izquierda y su incisiva participación en el movimiento de economía solidaria, a través de la Caritas brasileña. Posteriormente, como contrapunto, se analizan los lazos políticos entre 
agentes religiosos y parlamentarios para la formación y el apoyo de las carismáticas estaciones de televisión Canção Nova y TV Século XXI.

Palabras clave: Catolicismo brasileño. Teología de la Liberación. Renovación Carismática Católica. Economía Solidaria. Televisión Católica.

Data de recebimento: 31/07/2019

Data de aceite: 08/10/2019 


\section{Introdução}

O catolicismo no Brasil efetivamente desfrutou de muitas regalias graças a sua antiga posição de religião oficial, o que contribuiu historicamente para a preservação de sua hegemonia na sociedade brasileira. Mesmo que ao longo de décadas venha apresentando significativa redução no número de adeptos - $89 \%$ da população em 1980, diminuindo para 64,6\% em 2010 -, de acordo com dados do censo do Instituto Brasileiro de Geografia e Estatística (IBGE), o catolicismo ainda permanece como maioria numérica no campo religioso brasileiro. Desse modo, é possível afirmar que tal maioria exerce funções, ocupando cargos nos mais variados setores da vida social, tendo participação incisiva em atividades que vão desde as exclusivamente religiosas até outras, de caráter secular, nas áreas da política e da economia.

Tal participação pode ser evidenciada no cenário eleitoral de 2018, em que grupos religiosos católicos assumiram posturas diferentes e se posicionaram em campos opostos: de um lado a Conferência Nacional dos Bispos do Brasil (CNBB), pastorais sociais e as Comunidades Eclesiais de Base (CEBs), demonstrando posicionamento político alinhado à esquerda, e do outro a Renovação Carismática Católica (RCC), compactuando e defendendo posições da direita brasileira. Mas para melhor compreensão da polarização dos grupos católicos, faz-se necessária uma retomada quanto ao surgimento deles e ao seu contexto histórico, analisando o início de sua atuação no campo político e os aspectos que dele derivam, por exemplo, o desenvolvimento de práticas econômicas também distintas. A partir disso, objetiva-se analisar e destacar aspectos e trajetórias de cada um desses segmentos católicos e seus desdobramentos políticos e econômicos.

Metodologicamente, este artigo parte de prévio levantamento de dados qualitativos, realizado por meio de revisão bibliográfica de autores que abordaram temáticas relevantes nos estudos do cristianismo da libertação (LÖWY, 2016), Renovação Carismática 
Católica (PRANDI, 1996) e economia solidária (SINGER; SOUZA, 2000; SOUZA, 2013), de modo a revisitar e destacar aspectos pertinentes do contexto histórico de tais movimentos; pesquisa documental em sites, periódicos e mídias sociais maristas, principalmente da União Marista do Brasil (UMBRASIL) e do Instituto Marista de Solidariedade (IMS); e pesquisa de campo sobre a atuação de parlamentares vinculados ao movimento carismático.

A igreja se posicionou institucionalmente pela primeira vez em relação aos problemas sociais no ano de 1891, com o papado de Leão XIII e sua encíclica Rerum Novarum ("Das coisas novas" em português), que marcou o início do chamado catolicismo social (OLIVEIRA, 2001). A Doutrina Social da Igreja se posicionou de modo a contrapor, por um lado, uma corrente capitalista e, por outro, o socialismo ateísta, consolidando-se como terceira via cristã, tendo atuação importante em âmbito nacional no governo Vargas, que será tratado a posteriori (SOUZA, 2002). Ainda no contexto mundial, entre os anos de 1962 e 1965, ela avançou de maneira progressiva, mais uma vez, com o Concílio Vaticano II, iniciado durante o papado de João XXIII e encerrado no de Paulo VI, durante o período da Guerra Fria.

A palavra-chave desse concílio foi aggiornamento, termo de origem italiana que significa atualização, ou seja, consistia na adaptação da igreja aos novos tempos a partir do avanço da secularização. As diretrizes aprovadas em Roma possibilitaram que a igreja dialogasse com o mundo secular, modernizando-se. Isso implicou na mudança do idioma das missas, que passaram a ser realizadas não mais em latim, mas sim na língua vernácula. Além disso, a igreja se racionalizou, estabelecendo mais relações com a ciência, tornando-se menos mágica, portanto: fazendo do milagre algo raro e burocraticamente reconhecido (PRANDI; SANTOS, 2015). Nesse contexto, inicia-se um momento de valorização, não só de sacerdotes, mas sobretudo da atuação dos leigos em favor da instituição religiosa.

Esse fator foi fundamental no Brasil, com destaque, a partir dos anos 1970, para o desembarque de dois movimentos distin- 
tos: a RCC, de origem norte-americana, e as CEBs (PRANDI; SOUZA, 1996). Assim, a fundação e expansão das emissoras televisivas católicas TV Século XXI e Canção Nova estão atreladas fundamentalmente à eleição de parlamentares leigos vinculados à RCC. Em uma relação de mútuo apoio, observa-se a atuação deles em prol de tais emissoras televisivas, buscando obter a concessão pública via Ministério das Comunicações. Em troca, receberam desses canais relevante suporte político-eleitoral no tocante à promoção de suas candidaturas, em um processo que envolve, ao mesmo tempo, a agência de sujeitos religiosos, públicos e privados.

Já em relação às CEBs, os agentes políticos atuaram como um dos principais contrapontos do período ditatorial militar, integrando a base de importantes movimentos sociais (DOIMO, 1995). E mesmo após seu refluxo, a preocupação e dedicação dos esforços para combater injustiças sociais e a desigualdade (típicos da Teologia da Libertação) continuaram vivas nas atividades do movimento de economia solidária (SOUZA, 2013).

\section{A participação da Igreja na política e a Teologia da Liber- tação}

No final da década de 1950, marcada pela emergência de uma série de movimentos diferentes no clero - dentre eles os tradicionalistas, modernizadores conservadores e reformistas -, destacou-se como personalidade mais progressista o arcebispo de Olinda e Recife, dom Helder Câmara, responsável pela instituição da CNBB - Conferência Nacional dos Bispos do Brasil - e pela chamada "teologia do desenvolvimento", que questionava a pobreza extrema que recaía sobre o povo nordestino (MAINWARING, 1989).

No início da década de 60 surgiu no cenário mundial uma nova tendência intitulada "Esquerda Católica", influenciada diretamente por ideais teológicos franceses de Padre Lebret e Emmanuel Mounier, assim como dos ideais presentes na Revolução Cubana. 
Nesse momento, a Juventude Universitária Católica (JUC) radicalizou-se e aproximou-se dos ideais esquerdistas. A partir da emissão de documento pioneiro apresentado, Algumas diretrizes para um ideal histórico para o povo brasileiro, líderes da JUC denunciaram os males do capitalismo, buscando por uma estrutura social mais justa1:

Reivindicavam a substituição da economia anárquica baseada no lucro, por uma economia organizada de acordo com princípios humanos - um objetivo que, na prática, exigiria a "nacionalização dos setores produtivos básicos" (LÖWY, 2016, p.145).

A publicação desse documento da Esquerda Católica, em adição à encíclica Rerum Novarum e a Conferência de Medellin, na Colômbia (1968) - outro momento em que a Igreja Católica entra em reflexão sobre si e sua atuação -, foram seminais para o desenvolvimento do cristianismo da libertação na América Latina. Quanto à ideia de radicalização, ela estava relacionada às novas práticas sociais e políticas dos ativistas católicos: participação no movimento estudantil, em aliança com a esquerda secular, apoio às lutas sociais e compromisso com a educação popular. Destacase aqui o Movimento pela Educação Básica (MEB), baseado na pedagogia de Paulo Freire, que tinha como objetivo não só a alfabetização dos mais pobres, mas também conscientizá-los para se tornarem "agentes de sua própria história". No ano de 1962, os militantes da JUC e do MEB criaram a Ação Popular (AP), movimento político não-confessional dedicado à luta pelo socialismo e ao uso do método marxista (LÖWY, 2016).

Em 1964, eclodiu o Golpe Militar, com ele a ditadura e uma série de mudanças decorrentes. Durante esse período, a esquerda foi esfacelada por causa da oposição ao governo militar, sendo seus principais representantes perseguidos, torturados e exilados; a Igreja Católica, as CEBs e outros órgãos integraram então a oposição, abrigando perseguidos e em certas localidades compondo

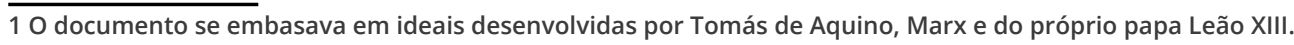


Televisão e autogestão: dois caminhos trilhados pelo catolicismo no Brasil André Ricardo de Souza • Breno Minelli Batista • Giulliano Placeres

até mesmo guerrilhas. Em um segundo momento, no período do Ato Institucional 5 (Al-5), em 1968, a brutalidade e a intensidade das perseguições e torturas caracterizaram o auge da repressão e da própria ditadura, um momento que representou uma ruptura no avanço progressista do papel da Igreja (LÖWY, 2016).

Porém, em maio de 1970, durante uma visita a Paris, dom Helder Câmara quebrou o silêncio e denunciou de maneira inédita o uso da tortura pelos governantes do regime militar brasileiro, tornando-se alvo de campanhas violentas de setores conformistas formados por autoridades e parte da imprensa no Brasil, chegando a ser chamado de "um Fidel Castro de batina que pertence à máquina de propaganda do Partido Comunista" (LÖWY, 2016, p. 150).

No mesmo período, as CEBs começaram a crescer rapidamente com o apoio de sacerdotes radicais, sendo em sua maioria ordens religiosas femininas. As CEBs objetivavam a congregação de pessoas do segmento populacional mais pobre, buscando conscientizá-los da importância de se organizarem para demandar seus interesses ${ }^{2}$. Desse modo, nota-se a instrumentalização do Evangelho que, ao mesmo tempo, "conscientiza" e atribui um sentido cristão à luta política (MACHADO; MARIZ, 1997). Além disso, vale ressaltar que dom Aloisio Lorscheider se tornou presidente da CNBB, interrompendo o posicionamento da instituição, que até então era neutro, para uma postura de grande mudança em prol da defesa dos direitos humanos.

Nesse contexto de ditadura que atingia toda a América Latina, emerge uma nova força cultural e religiosa fundamentada em ideias de igualdade social e direitos humanos, buscando combater com a fé as injustiças sociais feitas aos mais pobres: a Teologia da Libertação (BOFF, 2010). Tendo como base os trabalhos de Hugo Assmann, que uniu filosofia marxista com temas do cristianismo, o padre peruano Gustavo Gutierrez publicou o livro Teologia da

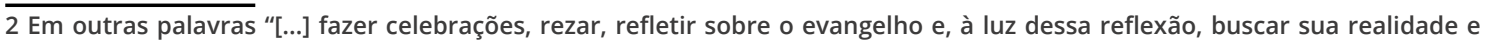
partir para uma ação transformadora." (MACHADO \& MARIZ, 1997, p. 72) 
Libertação: perspectivas, obra que fundamentou os ideais previamente citados no ano de 1971 (SILVA, 2006).

Além dessa obra, a publicação da tese de doutorado de Leonardo Boff na Universidade de Munique, Alemanha, auxiliou nos moldes da construção teórica da teologia, tornando-se assim figura central do catolicismo de libertação até os dias atuais ${ }^{3}$. Ele e o irmão Clodovis, por meio de textos e orientações políticas e espirituais às pessoas da Igreja, educaram toda uma geração de líderes católicos. Tal perspectiva teológica prossegue influenciando pastorais sociais e organismos católicos, como a Cáritas.

Embora a Teologia da Libertação tenha refluído, em grande medida por parte da posição restauradora do papa João Paulo II, da volta de linhas conservadoras para dioceses e para a própria CNBB e da saída de lideranças militantes das CEBs para integração de novos movimentos, como Partido dos Trabalhadores (PT), Movimento dos Sem Terra (MST) e Central Única dos Trabalhadores (CUT) (PRANDI; SINGER, 1996), ela nunca deixou de ter influência sobre parte do catolicismo brasileiro. Tal continuidade é evidenciada principalmente no movimento de economia solidária.

\section{O engajamento católico no movimento brasileiro de economia solidária}

Historicamente, as iniciativas de economia solidária surgiram a partir do apoio de grupos católicos, sindicatos, universidades, órgãos públicos e organizações não governamentais (ONGs). Porém, dentre esses atores sociais que envidaram esforços para o desenvolvimento da economia solidária, cabe a esta seção destacar o papel da igreja e sua moral, tradicionalmente coletivista e contrária às relações próprias do capitalismo (LÖWY, 1998; SWEDBERG, 2005). A atuação da Igreja Católica tem como uma de suas bases a caridade cristã, assegurando auxílio gratuito aos necessitados.

3 Jesus Cristo libertador (1972) e Igreja, carisma e poder (1981) são marcos no desenvolvimento da Teologia da Libertação no país. 
Retomando aqui o papel da encíclica Rerum Novarum, no documento também foi proposto pelo papa Leão XIII a cooperação entre trabalhadores, junto a uma crítica ao liberalismo econômico e socialismo ateísta, além de suscitar ideias cooperativistas que viriam a ser implementadas por alguns padres no século XX (SOUZA, 2013).

Um exemplo sobressai, o do sacerdote diocesano espanhol José Maria Arizmendiarrieta, idealizador de uma cooperativa fabricante de aquecedores a gás na pequena cidade de Mondragón (região basca), que se desdobrou de tal maneira que gerou o internacional Complexo Cooperativo de Mondragón, maior experiência cooperativista do mundo (WHYTE; WHYTE, 1988). No contexto da reestruturação produtiva e forte concorrência do capitalismo, típicas dos anos 70, o complexo perdeu parte significativa de suas características iniciais, embasadas em práticas igualitárias e democráticas (KASMIR, 1996; LIMA, 2004).

No Brasil, o cooperativismo com inspiração autogestionária em ambiente católico ganhou força durante o governo Vargas (1930-1945), a partir do desenvolvimento do que foi chamado de círculos operários, com suas práticas sociais e economicamente inovadoras (SOUZA, 2002). No âmbito do circulismo, em 1950, o frade dominicano João Batista Pereira dos Santos, inspirado pelos conceitos filosóficos dos franceses Emanuel Mounier e Jacques Maritain, e integrando o movimento Economia e o Humanismo, que foi liderado pelo Padre Jean-Louis Lebret, voltou ao Brasil com o intuito de iniciar um empreendimento de grande importância. Junto a um círculo operário da zona sul da cidade de São Paulo, ele constituiu, com o auxílio de alguns intelectuais de classe média (dentre eles, Paul Singer), uma fábrica de móveis ligada a quatro lojas próprias, denominada Unilabor (CLARO, 2004).

A Unilabor foi originada em um galpão, com maquinário adquirido por meio de empréstimos bancários. Frei João Batista realizava parte dos trabalhos em conjunto com os demais operários e repartia de forma igualitária todo o lucro com os associados. $O$ trabalho realizado por João Batista representou uma das expres- 
sões mais nítidas das propostas do catolicismo social da época, configurado como a terceira via cristã (ÁVILA, 1965; CAMARGO et al, 1984; LIMA; SOUZA, 2014). A experiência era interpretada pelo frei e demais envolvidos como contraponto ao capitalismo, que gera e reproduz desemprego e pobreza, e ao socialismo ateísta da época, sendo que o empreendimento representava também uma experiência de aproximação entre igreja e operariado (SANTOS, 1964).

Também no âmbito do catolicismo nacional de meados do século XX foi instituída a Cáritas Brasileira (1956), na $3^{\text {a }}$ Assembleia Geral da Conferência Nacional dos Bispos do Brasil (CNBB), então sob o comando de dom Hélder Câmara4 . Desde o início, a Cáritas tomou como sua principal finalidade a organização em nível nacional de todas as obras sociais promovidas pela Igreja Católica no país. Contando com verbas direcionadas pelo governo dos Estados Unidos no contexto do programa Aliança para o Progresso, a Cáritas Brasileira deu início a suas atividades tendo como ponto de partida a distribuição de alimentos ${ }^{5}$ para segmentos populacionais em condição de pobreza. No entanto, a partir de 1960, começou atividades que envolviam a capacitação profissional com o intuito de "não só dar o peixe, mas ensinar a pescar".

Em seguida, no final da década de 1970, a instituição dedicou-se a organizar atividades de questionamento ao regime militar e de reivindicação de políticas públicas, sob clara influência da Teologia da Libertação. Estando presente em todas as dioceses brasileiras, as três fases da Cáritas são representadas pela passagem da "caridade assistencial para a promocional e depois para a libertadora" (CÁRITAS BRASILEIRA, 1991).

A Cáritas Brasileira começou praticando o que ela própria designa caridade assistencial, algo voltado pontualmente para pessoas tidas como necessitadas e indefesas. Com o fim daquele programa, em 1974, a Cáritas começou a

\footnotetext{
4 A CNBB foi a primeira conferência de bispos no mundo, sendo relevante na descentralização do poder na Igreja Católica. 5 Doados pelo Catholic Relief Services (CRS), orgão norte-americano.
} 
desenvolver um novo modelo de prática caritativa chamada por ela de promoção humana ou promocional. Já no contexto de expansão das Comunidades Eclesiais de Base (CEBs), esse segundo e intermediário modelo se caracterizou pela crítica ao assistencialismo anterior e pela ênfase na educação popular, voltada para o desenvolvimento comunitário. Finalmente, por ocasião do $12^{\circ}$ congresso latino-americano da entidade, ocorrido em Santo Domingo (República Dominicana) em 1986, a Cáritas começou oficialmente a desenvolver seu terceiro modelo, o da caridade libertadora (SOUZA, 2011, p. 202-203).

Sob o ideal de "caridade libertadora", nos anos 80 foram organizados pela Cáritas grupos de geração de trabalho e renda, intitulados de Programas Alternativos Comunitários (PACs), que contaram, em seu início, com financiamento a fundo perdido de agências de cooperação internacional (a alemã Misereor talvez seja o maior exemplo). Esses empreendimentos solidários espaIharam-se rapidamente por mais de vinte unidades federativas, apresentando prevalência rural:

(...) formados por agricultores familiares, pequenos proprietários, agregados, arrendatários, meeiros, sem-terra e assentados, todos com prática de agricultura de subsistência e de pequena criação de animais, e que muitas vezes não são atendidos por programas governamentais (SOUZA, 2007, p. 164).

A aglomeração dos PAC's formou o que a Cáritas nomeou Economia Popular Solidária. Nesse sentido, a utilização do termo "popular" é explicada pela opção de trabalhar com pessoas de baixa renda que se encontram marginalizadas pelo mercado de trabalho. A experiência mais relevante promovida pela Cáritas em economia solidária é o desenvolvimento de uma cooperativa de segundo grau (aquelas formadas por um conjunto de duas ou mais cooperativas), chamada Cooesperança, composta por aproximadamente duzentos grupos de produtores rurais e ligada à diocese de Santa Maria - RS. Ela teve início em 1989, a partir do 
Televisão e autogestão: dois caminhos trilhados pelo catolicismo no Brasil André Ricardo de Souza • Breno Minelli Batista • Giulliano Placeres

Banco Esperança, da diocese conduzida por dom Ivo Lorscheiter (SOUZA, 2013).

Amparada por outras entidades ${ }^{6}$, a Cáritas é protagonista na organização do Fórum Brasileiro de Economia Solidária, formado em 2003. Essa mobilização resultou na criação de um órgão específico vinculado ao Ministério do Trabalho e Emprego do Governo Lula: a Secretaria Nacional de Economia Solidária (SENAES), que se mantém em funcionamento, embora tenha se tornado uma subsecretaria durante o mandato de Michel Temer. A convergência de sua atuação política com a capilaridade nacional torna a Cáritas a principal entidade de organização e fomento de iniciativas no campo de economia solidária no país.

Vale ressaltar que, mesmo sendo o organismo católico de maior visibilidade no campo da economia solidária, a Cáritas não é a única entidade católica a se dedicar às iniciativas comunitárias de geração de trabalho e renda. Algumas pastorais sociais e congregações religiosas também se envolvem nacionalmente nesse campo de atuação, principalmente apoiando cooperativas de coleta seletiva e de reciclagem de lixo. No amplo conjunto de congregações religiosas ${ }^{7}$, destaca-se a do Instituto dos Irmãos Maristas das Escolas, com ênfase nas atividades realizadas pelo Instituto Marista de Solidariedade (IMS), organismo responsável pela organização de grandes feiras e de centros públicos de formação em economia solidária.

O IMS foi fundado em 1995 na cidade de Belo Horizonte-MG por religiosos dessa ordem vindos do Rio de Janeiro. Em seus anos iniciais, o instituto canalizou recursos a segmentos populares em condição de grande pobreza. Assim como a Cáritas, esse órgão marista deu início às suas atividades norteado pela chamada "caridade assistencial", apresentando, a posteriori, ênfase em políticas públicas, característico do catolicismo politizado de esquerda, sob influência da Teologia da Libertação. Porém, é importante destacar que, no primeiro semestre de 2018, o IMS encerrou suas atividades

6 Como por exemplo a Agência de Desenvolvimento Solidário (ADS), vinculada à CUT, a Rede Unitrabalho de pesquisadores universitários e a universitária Rede de Incubadoras de Cooperativas Populares.

7 Jesuítas, Franciscanos, Redentoristas, Claretianos, Salesianos e Dominicanos. 
em meio a um momento de crise política e econômica no Brasil. Os motivos concretos não foram ainda elucidados, sabendo-se apenas que a continuidade dos trabalhos em economia solidária dos maristas "descentralizou-se" para diversas localidades, principalmente para a região sul do país.

\section{RCC e os laços políticos de suas emissoras televisivas Século XXI e Canção Nova}

No escopo do Concílio Vaticano II, a Igreja Católica estabelece novas diretrizes e políticas de ação em relação a vários temas, dentre eles o da comunicação social. O decreto Inter Mirifica, também aprovado em Roma, traçou novas perspectivas relacionadas ao modo de a igreja se comunicar. Isso resultou no estreitamento de laços dela com governos e com a iniciativa privada em prol do desenvolvimento de empreendimentos de comunicação social conforme os interesses doutrinários católicos: (...) "este sagrado concílio chama a atenção para a obrigação de sustentar e auxiliar os diários católicos, as revistas e iniciativas cinematográficas, as estações e transmissões radiofônicas e televisivas" (CONCÍLIO VATICANO II. 1962-1965 - DECRETO INTER MIRIFICA, CAP. II ART. $\left.17^{\circ}\right)$.

A empreitada católica no Brasil rumo à entrada nos meios de comunicação televisivos deve-se a dois elementos essenciais, que se aglutinam a partir da ação política e ideológica projetada pela igreja a partir dos anos 80 . O primeiro consistia no combate ao avanço pentecostal e grande evasão de católicos. Diante disso, utilizou como trunfo a RCC, movimento que encontrava-se em expansão no país e que também havia começado a apoiar candidatos nas eleições (REIS, 2016). Em segundo plano, para adquirir emissoras próprias de televisão era necessário intensificar a tradicional articulação de favorecimentos de agentes religiosos e políticos, especialmente parlamentares. 
Televisão e autogestão: dois caminhos trilhados pelo catolicismo no Brasil André Ricardo de Souza • Breno Minelli Batista • Giulliano Placeres

Nesse contexto a Igreja Católica, especificamente o clero paulista, movimentou-se em prol de seus empreendimentos televisivos, havendo também abertura de espaço dentro de emissoras laicas ${ }^{8}$ Por meio de acordos políticos e também com agentes da iniciativa privada, foram levantados recursos para a criação de emissoras ligadas à instituição romana. A iniciativa tinha como objetivo fazer frente ao crescimento pentecostal. Sua expansão acelerou-se acentuadamente a partir da década de 80, período em que conquistaram visibilidade pública, espaço na televisão e também poder político partidário, com a eleição de parlamentares (MARIANO, 2008). Gradativamente, a Igreja Católica vem perdendo espaço para outras organizações religiosas e outras fontes de orientação de conduta individual, em face do Estado laico.

Mesmo sendo ainda hegemônica, seu maior engajamento no espaço político-partidário, através de representantes leigos em posse de mandatos parlamentares em ação análoga aos evangélicos, foi fundamental para prosseguir com influência significativa sobre a sociedade 9 . Alguns segmentos católicos passaram a se relacionar com diferentes agentes da esfera pública, em busca de apoio financeiro e político para seus projetos de criação e expansão de emissoras. De fato, o processo de implantação, manutenção e a ampliação de veículos de comunicação, sobretudo televisivos, envolve sempre relações de poder: simbólico, econômico e político, acumulado pelos agentes envolvidos (BOURDIEU, 1989). O engajamento católico direcionado ao campo político com objetivos midiáticos tem como principal base a Renovação Carismática Católica (RCC).

Trata-se de um movimento de leigos de classe média surgido nos Estados Unidos entre docentes e estudantes universitários ao final da década de 1960. Seu objetivo constituía-se na busca de uma forma de "renovação espiritual", mantendo contato com diferentes grupos evangélicos pentecostais, chegando dispostos

8 Missas seriam transmitidas ao vivo, com destaque para a do Santuário Nacional de Aparecida, veiculada pela TV Cultura desde 1987, e a do popular padre Marcelo Rossi na Rede Globo a partir de 2001.

9 Destaca-se, nesse sentido, o acordo assinado no Vaticano em 2008 entre o governo brasileiro e a Santa Sé, relativo ao estatuto jurídico da Igreja Católica no Brasil (Giumbelli, 2011). 
a brigar no território do amplo mercado religioso. O movimento carismático não tardou a se difundir para outros países, dentre eles o Brasil, o que ocorreu em 1969 por intermédio dos jesuítas norte-americanos do Texas, os padres Eduardo Dougherty, fundador da TV Século XXI, e Haroldo Rham ${ }^{10}$. Sua organização central é basicamente laica, tendo como base os grupos de oração (PRANDI, 1997). Os grupos no Brasil se estabeleceram inicialmente no município de Campinas-SP, embrião da RCC no país.

Contudo, o enraizamento e a expansão do movimento para todo o país dependeram de uma articulação entre os membros disseminados em todo o Brasil, somados aos esforços de Eduardo Dougherty junto a grupos de leigos religiosos. Assim, o crescimento da RCC tem contribuído para a busca de resistência demográfica por parte da Igreja Católica no Brasil (CARRANZA, 2000; MARIZ; 2003; PRANDI, 1997). No entanto, ressalta-se que, em seu conjunto, a RCC se constitui- como um movimento de leigos (não anticlerical), cujo desenvolvimento e autolegitimação na igreja nunca foi tranquilo. Enquanto alguns padres e bispos assumiram posições favoráveis, outros impediram sua implantação em suas paróquias e dioceses, dificultando sua expansão (CARRANZA, 2000; ORO 1996).

\section{TV Século XXI}

A TV Século XXI surgiu no ano 1999 na cidade de Valinhos, por intermédio do padre jesuíta norte-americano Eduardo Dougherty, um dos pioneiros do movimento carismático no Brasil. Com experiência nos meios de comunicação adquirida por sua experiência anterior no rádio, em 1983, lançou, pela TV Gazeta, o primeiro programa católico da televisão brasileira: Anunciamos Jesus. Este começou a ser gravado na Pontifícia Universidade Católica (PUC), no município de Campinas, interior do estado de São Paulo e ain-

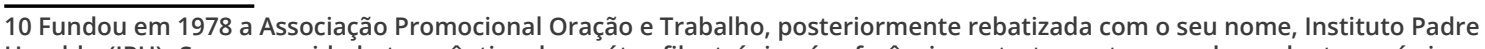
Haroldo (IPH). Sua comunidade terapêutica de caráter filantrópico é referência no tratamento para dependentes químicos, inclusive recebendo diversas premiações em virtude do trabalho realizado para com os jovens. 
da é exibido atualmente, completando 35 anos (SOUZA, 2008). Administrado pela Associação do Senhor Jesus (ASJ), sua entidade mantenedora, a emissora que iniciou suas atividades como uma produtora de televisão especializada em programas dramatúrgicos, contou com recursos oriundos do centro carismático americano de Dallas e também da família holandesa Brenninkmeyer, proprietária da cadeia de lojas de confecções C\&A. Dougherty montou estúdios com certo grau de sofisticação, produzindo novelas e demais programas voltados à devoção católica (ASSMANN, 1986; BENEDETTI, 2000; CARRANZA, 2000).

Entretanto, anterior à formação da emissora televisiva, a inspiração do padre para fundar a ASJ, também em Campinas, ocorreu por meio da Comunidade Católica Carismática de Aliança denominada "Jesus te ama", criada pelo religioso em conjunto a outros fundadores em 1973 (CARRANZA, 2001). Sua formalização como uma entidade jurídica se deu onze anos mais tarde, após um curso preparatório realizado pelo próprio Pe. Eduardo com membros que participavam de dois grupos de orações carismáticos à época: "Grupo de Oração Fonte de Água Viva" e "Plantão de Oração" (COMUNIDADE CATÓLICA DE ALIANÇA JESUS TE AMA, 2018). Ainda nos anos 80 , a comunidade possuía atuação relevante no município, em função dos múltiplos serviços espirituais que vinha prestando aos fiéis católicos, como os Seminários de vida no Espírito, que alcançavam 2000 participantes (CARRANZA, 2001).

Além disso, a comunidade também possuía um estúdio de rádio que dava apoio logístico à RCC nacional e internacional. Assim, entre 1979 e 1980, Dougherty fundou a ASJ, que futuramente viria a administrar seu canal religioso. Esta outra entidade sem fins lucrativos seria constituída juridicamente já no ano seguinte. Hoje, a associação ocupa um amplo espaço na cidade de Valinhos-SP, sede da TV Século XXI de $24.000 \mathrm{~m}^{2}$, bem diferente de sua primeira sede, constituída em uma pequena garagem de uma paróquia em Campinas (TV SÉCULO XXI, 2018). Dessa forma, contando com apoio financeiro de seu clube de sócios e de centros carismáticos internacionais, seu crescimento deu-se de forma progressiva. 
Finalmente, em setembro de 1987, deu-se a aquisição de um hotel em construção, na cidade de Valinhos, pelo valor de cento e vinte mil dólares, pagos em doze parcelas de dez mil dólares mensais (CANTO, 2011). O pioneirismo de Eduardo Dougherty com a criação do programa Anunciamos Jesus, que também contou com a participação de Jonas Abib (fundador da TV Canção Nova) por alguns anos, foi um de seus trunfos para impulsionar o crescimento da ASJ entre as décadas de 1980 e 1990, enquanto o movimento carismático se expandia rapidamente pelo Brasil:

\begin{abstract}
Em questão de meses, o programa pré-gravado (...) passaria a ser levado ao ar por mais de uma dúzia de estações. Ao mesmo tempo, um clube de telespectadores do programa (...) crescera rapidamente, passando de cerca de mil e trezentos a quase cinquenta mil membros (...) que faziam doações regulares na forma de pagamentos mensais. Esses recursos permitiram que a ASJ pagasse por mais tempo de transmissão e, somando-se às doações de entidades católicas da Holanda, Alemanha e Estados Unidos tornaram possível sua entrada na produção de materiais de vídeo comerciais competitivos para o mercado de propaganda de Campinas (DELLA CAVA; MONTERO, 1991, p. 75).
\end{abstract}

Durante grande parte da caminhada do religioso norte americano nos meios de comunicação, por mais de duas décadas esteve ao seu lado o ex-parlamentar Salvador Zimbaldi, que igualmente trabalhou para a TV Canção Nova. Em uma relação de mútuo apoio, o religioso contava com o seu respaldo para trazer recursos, sobretudo para a aquisição de uma emissora televisiva. Por outro lado, sempre apoiou suas candidaturas, desde quando se tornou vereador por Campinas até sua a escalada ao Congresso Nacional, quando eleito deputado federal. Retribuindo a concessão da TV Século XXI, conquistada em 1998 por meio do lobby político de Zimbaldi (à época no PSDB) e de seus correligionários, o Ministro das Comunicações Sérgio Motta e o Presidente Fernando Henrique 
Televisão e autogestão: dois caminhos trilhados pelo catolicismo no Brasil André Ricardo de Souza • Breno Minelli Batista • Giulliano Placeres

Cardoso, Dougherty participou de algumas campanhas às quais o parlamentar declarou seu apoio:

O canal Século XXI foi conseguido pelo servo, pelo servo de Deus: Salvador Zimbaldi, obrigado, querido! Agora você vai voltar, você vai voltar e vai servir Deus mais e mais vai servir a Igreja e todos os projetos e todos os valores da Igreja. A Igreja está precisando de você, meu querido irmão Zimbaldi, vai, vai evangelizar, vai naquilo com os valores de Jesus. Eu estou apoiando, eu estou incentivando vocês, por favor, vamos ajudar Zimbaldi deputado federal, muito obrigado, eu creio não tenho dúvida que é a vontade de Deus (ZIMBALDI, 2010).

Da mesma maneira que Dougherty por vezes discursou abertamente em favor do político, este também não media elogios ao comentar o trabalho prestado por aquele em prol da TV católica. Em um de seus programas jornalísticos foi exibida uma reportagem do quadro "Momento Brasília"11, na qual narra alguns fatos do cotidiano político na capital federal. Na ocasião, o repórter comentou acerca da liberação de mais um canal para a emissora, que havia sido obtida com o auxílio de Zimbaldi:

Nós estamos muito felizes aqui da TV século XXI, por dizer, pela alegria, pela ajuda pelo trabalho que o senhor tem nos dado nessa questão dos canais. O senhor agora acabou de liberar o canal 54 pra TV século XXI no município de Campinas (...) É a população de Campinas recebendo muito mais a TV século XXI nos seus lares graças ao senhor.

O parlamentar, católico declarado, promove em seu discurso a própria conquista, relacionando-a como um reflexo da pregação "da palavra de Deus", ao mesmo tempo em que também enaltece a figura do Pe. Eduardo e sua emissora televisiva. De um lado, os laços sociais entre Zimbaldi e o religioso proporcionaram rele-

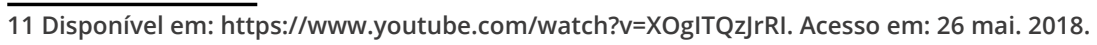


vante apoio eleitoral, conduzido pelo movimento carismático nas décadas de 1980 a 2000. Em contrapartida, como agente político responsável pela concessão da TV Século XXI, viabilizou sua expansão por meio da aquisição de diversas retransmissoras:

Quando eu coloco uma retransmissora, quando eu libero um canal como esse, eu prego a palavra de Deus também, eu sou um pregador, eu vou pregar a palavra de Deus através da boca do Pe. Eduardo, (...) daqueles que pregam a palavra de Deus através da TV século XXI (...) Porque eu tenho certeza, que eu fazendo o trabalho que procuro fazer, defender a TV século XXI perante o Congresso Nacional e perante Governo Federal, na sua pessoa eu tenho certeza que estou homenageando toda a população católica de todo o nosso Brasil. ${ }^{12}$

Além de Zimbaldi, destaca-se igualmente a relação política de Dougherty com o ativista político Odair Cunha, deputado federal do Partido dos Trabalhadores (PT-MG) apoiado explicitamente pelo religioso: "O trabalho que ele tem feito vai continuar (...) tem ajudado muito a TV Século XXI, a nossa expansão, conseguindo mais canais de televisão aí em Minas Gerais" (PROCÓPIO, 2012). Por fim, ressalta-se a participação de Flávio Augusto da Silva, mais conhecido como Flavinho, do Partido Social Cristão (PSC-SP), que, no ano de 2018, às segundas-feiras pela manhã, por aproximadamente duas horas, concomitante às suas atividades como deputado federal, exibiu junto a outros apresentadores a atração Você pode ser feliz. Durante o programa, cujo pano de fundo é a veiculação de mensagens católicas, em diversas chamadas o deputado utiliza seu capital político para convocar os telespectadores a contribuir financeiramente com as atividades promovidas pela Associação do Senhor Jesus. Por outro lado, o parlamentar utiliza-se da audiência propiciada pela emissora como palanque para a propaganda pessoal na promoção de seu mandato: transmite suas apresentações e participações na emissora ao vivo em sua página no Facebook.

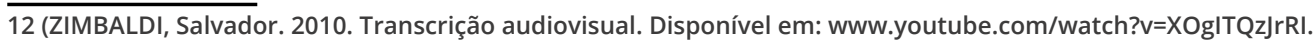




\section{TV Canção Nova}

A TV Canção Nova, atualmente maior emissora católica televisiva do Brasil, foi constituída em dezembro de 1989, fundada pelo padre salesiano, monsenhor ${ }^{13}$ Jonas Abib. Entretanto, antes de nos referirmos à criação e desenvolvimento da emissora, apontando os laços sociais com extensos vínculos políticos, faz-se necessário retomar parte da trajetória do sacerdote, resultado da constituição da Canção Nova quando ainda era uma comunidade. Ou seja, ainda fora das ondas do rádio e dos holofotes televisivos, Abib iniciou seu trabalho pastoral em 1968, junto a jovens. Os primeiros encontros foram realizados por meio da organização de retiros espirituais.

Após três anos, teve seu primeiro contato a RCC, da qual se tornou um de seus líderes. A oportunidade se deu por intermédio do padre Haroldo Rham, quando este realizava em Campinas-SP um treinamento de lideranças católicas. A experiência de "reavivamento espiritual" proporcionada pelo movimento impulsionou Abib na condução de seus trabalhos: a popularização dos encontros, promovidos inicialmente em escolas católicas fez surgir a necessidade de se buscar locais mais amplos. Nesse contexto, uma combinação de vínculos políticos foi determinante para que o objetivo fosse alcançado. Na área rural de Queluz-SP, região do Vale do Paraíba a que também pertence Cachoeira Paulista, havia terrenos herdados pela esposa do ex-prefeito do município - a propriedade do casal já havia sido ofertada ao religioso inclusive com a possibilidade de escolha entre três pontos diferentes ${ }^{14}$.

Ressalta-se a doação de um novo espaço feita por agentes públicos: direcionado para as atividades religiosas buscava-se, por meio dele, a construção de sua casa de encontros própria, dando

\footnotetext{
13 Título eclesiástico concedido pelos Papas a padres que se destacam por relevantes serviços prestados à Igreja. A iniciativa partiu de dom Benedito Beni, então bispo de Lorena-SP em 2007.

14 Disponível em: https://blog.cancaonova.com/queluz/historia-da-casa-de-maria/. Acesso em 21 mar. 2018.
} 
origem posteriormente em 1978, à "Comunidade Canção Nova". Ali foi feito o desafio a jovens que já acompanhavam o padre nos retiros para morarem juntos, deixando suas famílias e estudos e passando também a compartilhar finanças. Chamadas de Comunidades de Aliança e Vida no Espírito Santo elas constituem grupos de oração carismáticos ampliados, compostos por pessoas que se reúnem para louvor e dedicação a obras sociais (OLIVEIRA, 2009). A provocação feita por Jonas Abib fez surgir o marco fundador da Canção Nova, a primeira e maior dessas comunidades no Brasil. Acompanhando seu trabalho há quatro décadas está o casal de leigos, Wellington Da Silva Jardim, conhecido como Eto, e sua esposa Luzia Santiago, co-fundadores e administradores da Canção Nova.

A relação da Canção Nova com os meios de comunicação se deu no início de suas atividades: logo a fama do sacerdote se espalhou em São Paulo pelo Vale do Paraíba e sul de Minas Gerais, onde muitas rádios requisitavam sua presença e participação (CUSTÓDIO, 2013). Porém, apenas dois anos após o surgimento da comunidade, em 1980, a Canção Nova adquiriu a sua primeira emissora de rádio. A negociação se deu a partir da compra da antiga Rádio Bandeirantes AM de Cachoeira Paulista. A viabilização financeira do novo empreendimento foi possível a partir do Clube do Ouvinte ${ }^{15}$, iniciativa baseada em técnicas de marketing aplicado nas quais os espectadores da rádio contribuíam por meio de doações financeiras mensais, voltadas também para manutenção da comunidade (MARIANO, 1998; SOUZA, 2005), de tal modo que a entrada no meio televisivo também não tardaria.

No final do ano de 1989 surgia então a TV Canção Nova. Em seu primeiro programa foi veiculada uma missa inaugural a partir de uma retransmissora da TV Educativa (TVE) no Rio de Janeiro. A negociação seu deu por meio de um convênio firmado entre as duas emissoras, sendo que a católica alugava da secular carioca alguns de seus espaços da programação. As alianças políticas sus-

15 A estratégia de formação de clubes de ouvintes foi outra importação estadunidense feita pelas organizações católicas de mídia no Brasil. A primeira iniciativa desse tipo foi do padre redentorista Laurindo Rauber, em 1955, na Rádio Aparecida (BRAGA, 2004). 
Televisão e autogestão: dois caminhos trilhados pelo catolicismo no Brasil André Ricardo de Souza • Breno Minelli Batista • Giulliano Placeres

tentadas por intermédio de parlamentares são o resultado de sua expansão ${ }^{16}$ em nível nacional. A compra de sua primeira geradora, em 1997, resultou de acordo financeiro firmado com o casal sergipano, João Alves Filho (ex-deputado federal, ex-governador e prefeito de Aracajú) e a senadora Maria do Carmo Alves, do antigo PFL, (Partido da Frente Liberal), hoje integrantes do Democratas (DEM). Ambos detinham a propriedade da extinta TV Jornal, vendida por 4,5 milhões de reais ${ }^{17}$ divididos em vinte e quatro prestações ${ }^{18}$. A negociação deste canal foi intermediada por membros da Igreja Católica, com destaque para dom José Palmeira Lessa, Arcebispo de Aracaju e o frei franciscano Hans Stapel.

A aquisição feita no Nordeste também proporcionou o aumento do número de retransmissoras, por meio de acordos financeiros com prefeituras municipais. Estas, por sua vez, cediam suas antenas, exibindo a programação da emissora religiosa. Era necessário, no entanto centralizar as atividades televisivas em sua sede, Cachoeira Paulista ${ }^{19}$. Nesta ocasião, a Fundação João Paulo II, entidade mantenedora da Canção Nova solicitou ao Ministério das Comunicações outra estação geradora, no ano seguinte à compra feita em Aracaju. Para tanto, contou com o auxílio do ex-parlamentar tucano já mencionado Salvador Zimbaldi, que igualmente deu suporte na concessão da TV Século XXI. O parlamentar assinou um parecer favorável na Comissão de Ciência e Tecnologia, Comunicação e Informática da qual era, na ocasião, seu relator-presidente, aprovando a concessão da geradora. Em menos de um ano a solicitação foi prontamente atendida e a segunda geradora adquirida. Atualmente, a TV Canção Nova possui relevante cobertura em território nacional, com 350 retransmissores de sinais, fazendo chegar a todas as unidades federativas, além de três países: Israel, Portugal e Itália.

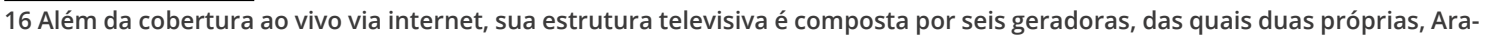
caju e Cachoeira Paulista, e outras quatro afiliadas: Belo Horizonte-MG, Brasília-DF, Curitiba-PR, e Florianópolis. Possui também três produtoras no exterior: Israel, Portugal e Roma.

17 Disponível em: https://acervo.veja.abril.com.br/\#/edition/32679?page=1\&section=1. Acesso em 22 de março de 2018.

18 Para a concretização do negócio, a Canção Nova necessitava aumentar seu orçamental mensal com a adesão de mais sócios colaboradores. Em substituição ao Clube do Ouvinte, foi lançado o projeto Dai-me Almas, campanha mensal para captar doações financeiras por meio da Fundação João Paulo II.

19 Cachoeira Paulista tem na Comunidade Canção Nova uma relevante fonte de recursos financeiros a partir do turismo. A cidade conta com uma pequena infraestrutura urbana, contendo caixas eletrônicos, posto médico, capelas, lanchonete, padaria, pousadas e locais para grandes eventos (OLIVEIRA, 2010).
} 
Televisão e autogestão: dois caminhos trilhados pelo catolicismo no Brasil André Ricardo de Souza • Breno Minelli Batista • Giulliano Placeres

Ressalta-se que a estreita relação de Zimbaldi com as emissoras católicas, estabelecida há décadas, começou a se deteriorar a partir de denúncias de ilicitudes por suposto envolvimento ${ }^{20}$ no chamado "Escândalo dos sanguessugas", em 2006. Após a divulgação desses fatos, os canais deixaram de apoiar o parlamentar, rompendo os laços estabelecidos anteriormente. Tal direcionamento resultou na perda significativa do respaldo católico, contribuindo diretamente para o revés do parlamentar nas eleições de 2014.

Durante muito tempo, a Canção Nova teve como um de seus expoentes o ex-deputado federal e ex-secretário da educação da capital paulista, Gabriel Chalita, que atuou junto ao ex-governador de São Paulo Geraldo Alckmin (PSDB) durante duas décadas. Os laços de amizade de Abib com Alckmin e Chalita são sólidos, como apontou o último em entrevista ${ }^{21}$, de tal maneira que o Monsenhor os procurou para atuarem como suas testemunhas de defesa na denúncia feita pelo Ministério Público da Bahia por incitação à discriminação religiosa, arquivada posteriormente pelo Supremo Tribunal Federal:

\begin{abstract}
Eu sou muito amigo dele, é um pai de todos nós. (...) Ele agora teve um processo contra ele que eu fui testemunha pra falar sobre as qualidades dele, uma história do Ministério Público da Bahia, de um dos livros dele, então eles me pediram eu fui pra defendê-lo, porque pra mim ele é a síntese desse homem bom, desse homem de Deus que tem essa visão que é muito difícil que é tocar no coração dos jovens (...) nesse processo o Alckmin foi testemunha dele também, o Alckmin é amigo deles há muito tempo deles também (...).
\end{abstract}

Segundo a acusação do Órgão, Abib, em seu livro Sim, Sim, Não, Não - Reflexões de cura e libertação, teria feito afirmações discriminatórias e preconceituosas contra a religião espírita e religiões

\footnotetext{
20 Folha Uol, 06 de agosto de 2006: Fundação revela como atuava a quadrilha. Disponível em: https://www1.folha.uol.com.br/ $\mathrm{fsp} / \mathrm{brasil/fc0608200607.htm.} \mathrm{Acesso} \mathrm{em} 05$ ago. 2018.

21 Entrevista pessoal realizada com Gabriel Chalita. São Paulo - 12 mai. 2017.
} 
de matriz africana, como a umbanda e o candomblé, incitando a destruição e o desrespeito a seus objetos de culto (SUPREMO TRIBUNAL FEDERAL, 2016). Alckmin, em abril de 2018, renunciou ao cargo de governador do estado de São Paulo para disputar as eleições presidenciais, e em seu lugar assumiu o vice Marcio França (PSB). Logo nas primeiras semanas após a sucessão ocorreu na capital paulista o evento de evangelização "Abraça São Paulo", realizado há mais de uma década pela Canção Nova, já fazendo parte do calendário oficial de eventos do município. Naquele ano foram comemorados os 40 anos da comunidade. França então participou das atividades promovidas na solenidade e, em entrevista ${ }^{22}$, relatou o apreço do ex-governador tucano pela Canção Nova, além de citar o início das transmissões televisivas na capital:

O Governador Alckmin tinha um carinho muito grande com a Canção Nova. Então a Canção Nova tem diversas parcerias, escolas, enfim, posto médico, atendimento, mas mais do que isso, a evangelização feita pela Canção Nova em todas as cidades, quarenta anos, um número bíblico, importante, marcado na bíblia por diversas passagens importantes e agora completando 40 anos, a Canção Nova vai começar uma nova fase com televisão na capital que também é importante (GOVERNO DO ESTADO DE SÃO PAULO, 2018).

A TV Canção Nova e o movimento carismático apoiaram a eleição de ao menos dois deputados federais eleitos no pleito de 2014: Eros Biondini, do Partido Trabalhista Brasileiro (PROS-MG), e o já citado Flavinho, que também apresenta programas pela TV Século XXI. Biondini foi responsável por coordenar as ações para a instalação da emissora em Minas Gerais; já Flavinho, além de participar por quase duas décadas nas atividades do canal de Jonas Abib, permaneceu durante 14 anos, residindo com sua família em três núcleos diferentes da Comunidade Canção Nova, inicialmente em Cachoeira Paulista e depois Cuiabá e Aracajú. Sua relevância

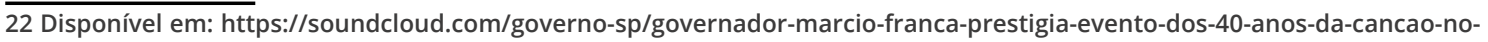
va-em-sp Acesso em 03 ago. 2018. 
junto à emissora e à RCC foi ascendente: com recorrente presença nas mídias católicas no rádio e na TV, apresentando programas, além da gravação de álbuns e publicação de livros, tornou-se figura destacada na RCC.

\section{Considerações Finais}

Como se pretendeu demonstrar, a Igreja Católica, mesmo apresentando contínua redução de adeptos, ainda exerce significativa influência na sociedade brasileira, seja por meio de órgãos influenciados pela Teologia da Libertação como a Cáritas Brasileira e a própria CNBB, seja pela atuação do movimento carismático. Ao longo da contextualização histórica e social realizada fica evidente, principalmente se colocadas em destaque as trajetórias da Teologia da Libertação e da RCC, o processo de construção e consolidação do que Paula Montero (2012) se refere como hegemonia discursiva católica.

Em outras palavras, graças à participação da Igreja Católica em um momento político bastante conturbado da história do Brasil, a ditadura militar, e ao seu pioneirismo e participação incisiva nas mídias televisivas, o catolicismo, legitimado pela sociedade, garantiu sua capacidade de influir e pautar a agenda política dos anos seguintes, assegurando a transmissão de seus valores para as normas da sociedade civil. Nota-se que a partir das diretrizes do Concílio Vaticano II, e posteriormente com a chegada da RCC ao Brasil, possibilitou-se maior inserção católica nos meios de comunicação televisivos. Para isso, foram intensificados de maneira relevante acordos e parcerias que transcendem o meio estritamente religioso para outros setores, como o político e o econômico. Tal direcionamento envolveu e ainda envolve diversas ações junto ao poder público, de modo a propiciar que a igreja concorra com grupos privados para a criação, manutenção e ampliação de emissoras de TV. 
Dessa maneira, os primeiros passos efetivos foram dados na década de 1980 por iniciativa dos pioneiros padres da RCC no Brasil: Eduardo Dougherty e Jonas Abib. As trajetórias televisivas de ambos começaram com a gravação de programas religiosos como o Anunciamos Jesus. Na atualidade, cada um é fundador e condutor de uma rede televisiva: Século XXI e Canção Nova, respectivamente. Mas para que essa realidade se concretizasse foram necessárias parcerias com diversos agentes, que incluíram a participação maciça de empresários, religiosos e, igualmente, atores da cena pública, sendo alguns aqui elencados, com destaque para o ex-deputado federal Salvador Zimbaldi e, na atualidade, Flávio Augusto da Silva.

Quanto à Teologia da Libertação e as CEBs, embora tenham atravessado um período de refluxo, seus ideais se mantiveram ativos e germinaram no movimento de economia solidária, tanto no cerne das atividades da Cáritas Brasileira (ligada à CNBB), quanto nas práticas do Instituto dos Irmãos Maristas das Escolas, no Brasil. Nota-se também que a Teologia da Libertação e as CEBs iniciaram um processo de retomada de suas práticas desde a eleição do papa Francisco, o argentino jesuíta Jorge Mario Bergoglio, que, a partir de seus posicionamentos sobre minorias e injustiças sociais, tem sido considerado um pontífice ainda mais progressista que João XXIII e Leão XIII, responsáveis pelo Concílio Vaticano II e pela encíclica Rerum Novarum, respectivamente.

Tanto a Teologia da Libertação quanto a RCC apresentaram, grosso modo, o mesmo ponto de partida histórico, ou seja, uma reação da Igreja Católica frente ao declínio progressivo no número de adeptos, seja para o capitalismo/socialismo, quanto para o pentecostalismo. Porém, de acordo com os dados previamente expostos, ambos os movimentos apresentam engajamentos políticos antagônicos (esquerda versus direita) e práticas econômicas distintas, como o empreendedorismo televisivo versus economia solidária. Tal fato se reflete nos posicionamentos desses grupos no cenário vigente, com os representantes da RCC se aproximando politicamente da Frente Parlamentar Evangélica com uma postura 
mais conservadora, enquanto a CNBB, por exemplo, segue uma proposta mais progressista, alinhando sua atuação com os ideais do atual pontífice.

\section{Referências}

ASSMANN, Hugo. A igreja eletrônica e seu impacto na América Latina. Petrópolis, Vozes, 1986.

ÁVILA, Fernando Bastos de. Solidarismo. Rio de Janeiro: Agir, $3^{a}$ ed, 1965.

BENEDETTI, Luiz Roberto. Templo, praça, coração: a articulação do campo religioso católico. São Paulo, Humanitas e FAPESP, 2000.

BOFF, Leonardo; BOFF Clodovis, Como fazer teologia da libertação. Petrópolis: Vozes, 2010.

BOURDIEU, Pierre. O poder simbólico. Fernando Tomaz (Trad.). Lisboa: DIFEL, 1989.

CAMARGO, Candido Procopio Ferreira de; SOUZA, Beatriz Muniz; PIERUCCI, Antônio Flavio. A Igreja Católica: 1945-70. In: FAUSTO, Boris (Org.). História geral da civilização brasileira. São Paulo:Difel, v. 11, 1984.

CANTO, Paulo de Tarso Leite do. Um projeto de vida na Igreja. Campinas, 2011. Dissertação (Mestrado em educação). Universidade Estadual de Campinas, Campinas, 2011.

CÁRITAS BRASILEIRA. Mística e metodologia da caridade libertadora. São Paulo, Loyola, 1991.

CARRANZA, Brenda. Catolicismo midiático. Aparecida: Idéias \& Letras, 2001. 
CARRANZA, Brenda. Renovação Carismática: origens, mudanças e tendências. Aparecida do Norte, SP: Editora Santuário, 2000.

CLARO, Mauro. Unilabor: desenho industrial, arte moderna e autogestão operária. São Paulo, SENAC, 2004.

COMUNIDADE CATÓLICA DE ALIANÇA JESUS TE AMA. Disponível em: www.comunidadejesusteama.org.br. Acesso em: 06 ago. 2018.

CONCÍLIO VATICANO II. 1962-1965. Decreto Inter Mirifica. Disponível em: www.vatican.va/archive/hist_councils/ii_vatican_ council/documents/vatii_decree_19631204_inter-mirifica_po.html. Acesso em: 3 dez. 2015.

CUSTÓDIO, Flávio Maia. Urbi et Orbi: Uma análise da programação televisual de duas emissoras de TV Católicas - Canção Nova e TV Aparecida. Dissertação (Mestrado em Comunicação e Semiótica), Pontifícia Universidade Católica de São Paulo, São Paulo, 2013.

DELLA CAVA, Ralph \& MONTERO, Paula. E o verbo se faz imagem: Igreja Católica e os meios de comunicação no Brasil, 19621989. Petrópolis, Vozes, 1991.

DOIMO, Ana Maria. A vez e a voz do popular: movimentos sociais e participação política no Brasil pós 70. Rio de Janeiro, Relume Dumará; ANPOCS, 1995.

GIUMBELLI, Emerson. O Acordo Brasil-Santa Sé e as relações entre Estado, sociedade e religião. Ciencias Sociales y Religión (Online), v. 14, p. 119-143, 2011.

GOVERNO DO ESTADO DE SÃO PAULO. Perfil oficial do Governo do Estado de São Paulo no Sound Cloud. Disponível em: https:// soundcloud.com/governo-sp. Acesso em 06 ago. 2018.

INSTITUTO MARISTA DE SOLIDARIEDADE. Disponível em: marista. edu.br/ims. Acesso em: 22 jul. 2017. 
KASMIR, Sharryn. The Myth of Mondragón. Cooperatives, Politics and Working-Class Life in a Basque Town. Albany, State University of New York Press, 1996

LIMA, Jacob Carlos. O trabalho autogestionário em cooperativas de produção: o paradigma revisitado. Revista Brasileira de Ciências Sociais, v. 19, n. 56, 2004.

LIMA, Jacob Carlos; SOUZA, André Ricardo de. Trabalho, solidariedade social e economia solidária. Lua Nova, n. 93, 2014, p. 139-168.

LÖWY, Michael. O que é Cristianismo da Libertação: religião e política na América Latina. 2. ed. - São Paulo: Editora Fundação Perseu Abramo: Expressão Popular, 2016.

LÖWY, Michael. Ética católica e o espírito do capitalismo: o capítulo da sociologia da religião de Max Weber que não foi escrito. Cultura Vozes. Petrópolis, Vozes. v. 92, n.1, 1998, p. 86-100

LÖWY, Michael. Política e religião na América Latina: a igreja brasileira e a política. In: A guerra dos deuses: religião e política na América Latina. Petrópolis, Vozes, 2000.

MAINWARING, Scott. Igreja católica e a política no Brasil: 19161985. São Paulo, Brasiliense, 1989.

MARIANO, Ricardo. Renovação carismática católica: movimento mágico, moralista e proselitista. Plural, 5, 196-200, 1 sem. 1998. MARIANO, Ricardo. Crescimento pentecostal no Brasil: fatores internos. REVER (PUCSP. Online), v. 4, p. 68-95, 2008.

MARIZ, Cecília Loreto. A Renovação Carismática Católica: uma igreja dentro da Igreja? Civitas, Porto Alegre, v. 3, n.1, p. 169-186, 2003.

MONTERO, Paula. Controvérsias religiosas e esfera pública: repensando as religiões como discurso. Religião \& Sociedade. v. 32, $n^{\circ} 1$, p. 167-183, 2012. 
OLIVEIRA, Eliane M. A "vida no espírito" e o dom do ser Canção Nova. In: CARRANZA, Brenda; MARIZ, Cecília; CAMURÇA, Marcelo (orgs). Novas comunidades católicas: em busca do espaço pós-moderno. Aparecida, Ideias \& Letras, 2009.

OLIVEIRA, Jefferson Rodrigues de. Hierópolis Carismática em Cachoeira Paulista: Canção Nova e as peregrinações pós-modernas. In: - Espaço e Cultura, Rio de Janeiro: UERJ, PEAGERC/ NEPEC, 2010, p. 71-80.

OLIVEIRA, Valter de. Evolução da doutrina social da igreja: histórico do pensamento dos papas e dos bispos do Brasil de Leão XIII a Pio XII em relação à questão social, ao capitalismo e ao socialismo. São Paulo, 2001. Dissertação (Mestrado em História), Universidade de São Paulo, São Paulo, 2001.

ORO, Ari Pedro. Ação evangélica, reação católica. Petrópolis, Vozes, 1996.

PRANDI, Reginaldo. Um sopro do espírito: a renovação conservadora do catolicismo carismático. São Paulo: Edusp/Fapesp, 1997.

PRANDI, Reginaldo; SANTOS, Renan William dos. Mudança religiosa na sociedade secularizada: o Brasil 50 anos após o Concílio Vaticano II. Contemporânea - Revista de Sociologia da UFSCar, v. 5, n. 2, jul.-dez. 2015, p. 351-379.

PROCÓPIO, Carlos Eduardo Pinto. Carismatismo católico e eleições no Brasil. Ciencias Sociales y Religión. v. 14, p. 75-99, 2012.

REIS, Marcos Vinícius de Freitas. Política e religião: participação política dos católicos carismáticos do Brasil. São Carlos, 2016. Tese (Doutorado em Sociologia). Universidade Federal de São Carlos, São Carlos, 2016.

SANTOS, Carlos Roberto Praxedes dos. A TV pública não pública: como surgem e se mantêm as televisões não comercias de Santa Catarina. Curitiba, 2017. 301 f. Tese (Doutorado em 
Comunicação e Linguagens) - Universidade Tuiuti do Paraná, Curitiba, 2017.

SANTOS, João Batista Pereira. Os chifres do diabo: capitalismo comunismo. São Paulo: SAL, 1964.

SWEDBERG, Richard. Max Weber e a Idéia de Sociologia Econômica. Rio de Janeiro: UFRJ; São Paulo: Beca Produções Culturais, 2005

SÉCULO XXI. Disponível em: http://www.tvseculo21.org.br. Acessado em: 03 de outubro de 2018.

SINGER, Paul; SOUZA, André Ricardo de. A economia solidária no Brasil: a autogestão como resposta ao desemprego. São Paulo, Contexto, 2000.

SOUZA, André Ricardo de. Igreja católica e mercados: a ambivalência entre a solidariedade e a competição. Religião e Sociedade, Rio de Janeiro, v. 27, n.1, p. 156-174, julho 2007.

SOUZA, André Ricardo de. As investidas católicas na mídia. REVER (PUCSP), v. 9, p. 27-45, 2008.

SOUZA, André Ricardo de. Igreja in concert: padres cantores, mídia e marketing. São Paulo, Annablume e Fapesp, 2005.

SOUZA, André Ricardo de. Caridade, conservação e mudança social. In: BURITY, Joanildo: ANDRADE, Péricles (Orgs.). Religião e cidadania. São Cristóvão, EDUFS; Recife, FUNDAJ, 2011.

SOUZA, André Ricardo de Os laços entre igreja, governo e economia solidária. São Carlos, EDUFSCar e FAPESP, 2013.

SOUZA, André Ricardo de; PRANDI, Reginaldo . A carismática despolitização da Igreja Católica. In: PIERUCCl, Antônio Flávio; PRANDI, Reginaldo. (Org.). A realidade social das religiões no Brasil: religião, política e sociedade. 1ed. São Paulo: Hucitec, 1996, v. 1, p. 59-91. 
Televisão e autogestão: dois caminhos trilhados pelo catolicismo no Brasil André Ricardo de Souza • Breno Minelli Batista • Giulliano Placeres

SOUZA, Jessie Janet. Círculos operários: a Igreja Católica e o mundo do trabalho no Brasil. Rio de Janeiro, EDURJ e FAPERJ, 2002.

SUPREMO TRIBUNAL FEDERAL. Disponível em: www.stf.jus.br/ portal/principal/principal.asp. Acesso em: 10 ago. 2017.

UNIÃO MARISTA DO BRASIL. Disponível em: www.umbrasil.org.br. Acesso em: 20 ago. 2018.

ZIMBALDI, Salvador. Campanha eleitoral de Salvador Zimbaldi. Youtube. 26 jul. 2010. 2010. Transcrição audiovisual. Disponível em: https://www.youtube.com/watch?v=3xV-my-2vQE).

WHYTE, Willian Foote; WHYTE, Kathleen King. Making Mondragón: the growth and dynamics of the Worker Cooperative Complex. Ithaca, ILR Press, 1988. 